\title{
Study on the preparation of Ag doped TiO2 catalyst by microwave hydrothermal method and its photocatalytic activity
}

\author{
Yuejie $\mathrm{Lu}^{1, \mathrm{a}}$, Xin Wang ${ }^{1, \mathrm{~b}}$ and Xianjun $\mathrm{Bi}^{1 \mathrm{C}^{\mathrm{C}}}$ \\ ${ }^{1}$ Institute of Chemistry and Chemical Engineering, Yunnan Normal University, Kunming 650500, \\ Yunnan, P. R. China \\ a1079260276@qq.com, b965184394@qq.com, cbixj159@aliyun.com
}

*The corresponding Author

Keywords: Microwave hydrothermal; Ag doping; TiO2 photo catalyst; Microwave and Ultrasound enhanced; Photocatalytic activity

\begin{abstract}
Silver doped $\mathrm{TiO} 2$ catalyst $\mathrm{TiO} 2-\mathrm{Ag}$ was synthesized by microwave hydrothermal method when the optimal condition was selected with orthogonal and single factor tests. The photocatalytic activity of $\mathrm{TiO} 2-\mathrm{Ag}$ catalyst was further enhanced by the microwave and ultrasonic assisted with using methyl orange as pollutants. And the TiO2-Ag was characterized by the XRD, SEM, EDS, TG-DSC-DTG, BET and ICP-AES. The results showed that the optimal conditions of TiO2-Ag prepared by microwave hydrothermal method was $\mathrm{n}(\mathrm{Ag}+) / \mathrm{n}(\mathrm{Ti} 4+)=0.003$, microwave power $600 \mathrm{~W}$, reacting time for $3 \mathrm{~h}$ at $140^{\circ} \mathrm{C}$ and calcining time for $3 \mathrm{~h}$ at $550^{\circ} \mathrm{C}$. The TiO2-Ag had higher photocatalytic activity and stability which get better degradation efficiency in a relatively short period of time for the degradation of organic pollutants when the microwave and ultrasonic assisted optimization condition. The structure characterization of the catalyst showed that the microwave hydrothermal synthesis of $\mathrm{Ag}$ doped $\mathrm{TiO} 2$ photo catalysts had $\mathrm{OH}$ multi-surface, high crystallinity and large surface area, and inhibited the phase transformation of $\mathrm{TiO} 2$ from anatase to rutile. At the same time, the doped catalyst prepared by microwave hydrothermal process was feasible method with high rate the use of drugs.
\end{abstract}

\section{Introduction}

The transition of human development, unreasonable use and the free disposal of life and production of waste has brought a fatal threat to the survival of our homeland. Human beings need to improve the serious environmental problems, and photocatalytic technology has a good application prospect in the field of pollution control[1,2]. The TiO2 is widely used as photocatalyst because it has both high photocatalytic degradation rate and good stability and it is synthesized with the low cost and mild reaction condition. However, the TiO2 photocatalyst can only absorb the UV light, and the absorption efficiency of visible light of $\mathrm{TiO} 2$ is low, which restricts the improvement of photocatalytic degradation efficiency.

In recent years, the modification of $\mathrm{TiO} 2$ photocatalyst, the optimization of synthesis conditions and preparation methods have become the focus of many scholars, so that the photocatalyst can be better used in real life. In a large number of experiments in the past, the research group prepared metal and nonmetal doped $\mathrm{TiO} 2$ photocatalyst in ionic liquid by microwave assisted sol-gel method, and the photocatalytic activity was studied and the experimental results were finally obtained $[3,4]$. However, the synthesis time of this method is longer, and $\mathrm{N}$-methyl imidazole and other raw materials being expensive, having toxic and harmful to people's health. Research found in our experiment conditions that heating by microwave radiation from inside to outside let the reaction system was uniformly heated which could increase photocatalytic activity of $\mathrm{TiO} 2$. And more $\mathrm{Er}$ doped $\mathrm{TiO} 2$ photocatalyst prepared by the microwave hydrothermal synthesis showed better photocatalytic activity[5]. $\mathrm{Ag}$ doped $\mathrm{TiO} 2$ can effectively inhibit the recombination of photogenerated electrons and holes and promote the transfer of photogenerated electrons, so as to 
improve the degradation efficiency of under visible light[6,7]. And more Ag+ also has bactericidal effect. Therefore, the synergistic antibacterial effect of $\mathrm{Ag}+$ and $\mathrm{TiO} 2$ can further improve the photocatalytic activity of the catalyst. In this paper, $\mathrm{Ag}$ doped $\mathrm{TiO}_{2}$ photocatalyst was prepared by microwave hydrothermal method. The photocatalytic degradation efficiency of $\mathrm{TiO}_{2}$ catalyst was further improved by optimizing the preparation conditions and microwave assisted degradation of organic pollutants.

\section{Experimental Section}

Experimental Reagents and Instruments. The Reagent: Silver nitrate (AR), butyl titanate (AR), ethanol (AR), nitric acid, methyl orange, ultra-pure water.

Instrument: $\mathrm{XH}-800 \mathrm{~S}$ microwave hydrothermal parallel synthesis and XH-300UL synthetic instrument computer microwave ultrasonic wave combined catalytic.

Preparation of $\mathrm{TiO}_{2}-\mathbf{A g}$ Catalyst. Adding $17.5 \mathrm{~mL}$ ethanol into beaker after taking $3.4 \mathrm{~mL}$ tetrabutylorthotitanate, and stirring to form A solution. In different material $n\left(\mathrm{Ag}^{+}\right) / \mathrm{n}\left(\mathrm{Ti}^{4+}\right)$ of silver nitrate dissolved in ultra-pure water to obtain B solution. the B solution was added drop wise into A solution, and switched to PTFE high pressure reactor, then changing the microwave hydrothermal parallel synthesis of microwave power, hydrothermal reaction temperature and reaction time. Reaction, filtration, ultra pure water washing made white filter cake. Finally, the sample was fully grinded after the vacuum drying oven dried for $3 \mathrm{~h}$. The $\mathrm{Ag}$ doped $\mathrm{TiO}_{2}$ photocatalyst $\mathrm{TiO}_{2}-\mathrm{Ag}$ was prepared in a high temperature box type resistance furnace at different temperatures and placed in dryer.

Photocatalytic Activity Test. The photocatalytic activity of $\mathrm{TiO}_{2}-\mathrm{Ag}$ catalyst was tested with refer to literature ${ }^{[8-10]}$. changing the reaction time to do photocatalytic reaction respectively under the degradation conditions for UV, MW, UV-MW and UT-UV-MW in computer combinated of microwave and ultrasonic catalysis synthesis instrument. After take the supernatant liquid, The determination of removal efficiency of $\mathrm{TiO}_{2}-\mathrm{Ag}$ were synthesized by microwave hydrothermal method. With the degradation rate of formula calculated the degradation rate of methyl orange: $\eta=$ $\left(A_{0}-A\right) / A_{0} \times 100 \%\left(A_{0}\right.$ and $A$ respectively before and after the absorbance of methyl orange degradation).

\section{Results and Discussion}

Photocatalytic Property.

1) Effect of Ag doped on photocatalytic activity

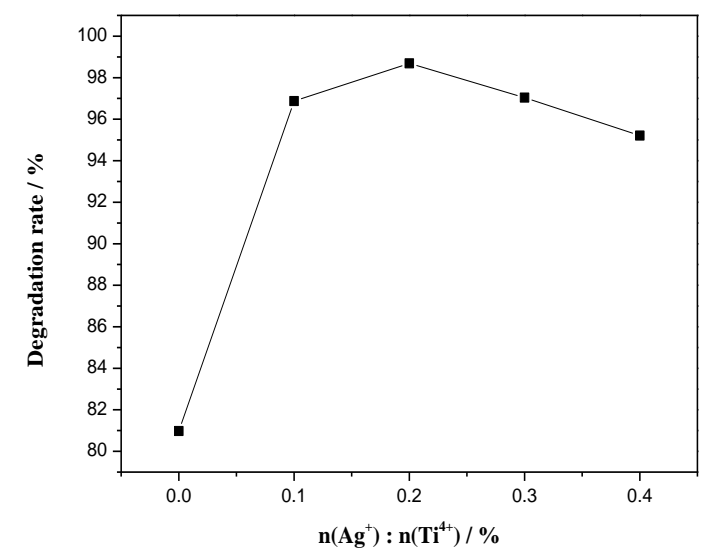

Figure 1. The influence of $n\left(\mathrm{Ag}^{+}\right) / n\left(\mathrm{Ti}^{4+}\right)$ mole ratio on photocatalytic activity of $\mathrm{TiO}_{2}-\mathrm{Ag}$ 
In order to investigate the effect of $\mathrm{n}\left(\mathrm{Ag}^{+}\right) / \mathrm{n}\left(\mathrm{Ti}^{4+}\right)$ on the degradation rate, $\mathrm{TiO}_{2}-\mathrm{Ag}$ catalyst doped with different proportion was used for methyl orange degradation in the self-assembly of highpressure mercury lamp device after $50 \mathrm{~min}$, the results as shown in Fig. 1. Degradation rate of $\mathrm{TiO}_{2-}$ $\mathrm{Ag}$ when $\mathrm{n}\left(\mathrm{Ag}^{+}\right) / \mathrm{n}\left(\mathrm{Ti}^{4+}\right)=0.003$ was $98.69 \%$ which obviously higher $17.71 \%$ than $80.98 \%$ of pure $\mathrm{TiO}_{2}$. Due to noble metal Ag as a separate center of electrons and holes inhibiting the composite of e- and $\mathrm{h}^{+}$could prolong the life of photogenerated electrons and holes ${ }^{[11,12]}$, the catalyst had higher photocatalytic activity. Doping type catalyst for methyl orange degradation rate was relatively high, relatively narrow scope, small changes. This result indicated that the $\mathrm{Ag}$ doped $\mathrm{TiO}_{2}$ could effectively improve the photocatalytic activity and the influence of doping amount of small fluctuation.

2) Microwave-Ultrasonic enhanced photocatalytic activity

Fig. 2 was the effect of reaction time on the degradation efficiency of $\mathrm{TiO}_{2}$-Ag catalyst under the conditions of MW, UV, UV-MW and UV-MW-UT in the computer microwave ultrasonic combination catalytic synthesis instrument. The degradation rate was $9.75 \%, 90.76 \%, 95.05 \%$ and close to $100 \%$ respectively by MW, UV, UV-MW and UV-MW-UT for 35 min degradation, while it was higher than $90 \%$ by UV-MW for 10 min after UT shock. The reasons might be that the ultrasonic shock made the contact area between the $\mathrm{TiO}_{2}-\mathrm{Ag}$ catalyst and the organic pollutant unit becoming larger, and the microwave radiation increased the number of hydroxyl radicals on the surface of the $\mathrm{TiO}_{2}-\mathrm{Ag}$. The result was that the degradation rate of the catalyst in different degradation conditions was UT-UV-MW $>U V-M W>U V>M W$. The results showed that microwave irradiation and ultrasonic vibration could enhance the effect of $\mathrm{TiO}_{2}-\mathrm{Ag}$ on photocatalytic degradation of organic pollutants under UV irradiation. At the same time, the degradation rate increased to a certain limit, then the degradation rate changed little, so there was an optimal degradation time to achieve better results in a short time.



Figure 2. Effect of reaction time on the photocatalytic efficiency of TiO2-Ag

XRD Analysis. XRD spectra of $\mathrm{TiO}_{2}-\mathrm{Ag}$ with different doping amount was given in Fig. 3. Jade5 analysis showed that XRD spectra of $\mathrm{TiO}_{2}-\mathrm{Ag}$ with $\mathrm{n}\left(\mathrm{Ag}^{+}\right) / \mathrm{n}\left(\mathrm{Ti}^{4+}\right)=0.001,0.002,0.003$ and 0.004 in accordance with standard anatase $\mathrm{TiO}_{2}$ peaks (PDF\#86-1157). The matching degree was high, and the matching rate of reciprocal (FOM) was 3.4, 1.7, 5.7 and 11.2. the grain size of anatase was estimated to $16.62,19.36,22.33$ and $27.43 \mathrm{~nm}$ according to the Scherrer formula $(\mathrm{D}=\mathrm{K} \lambda / \beta \cos \theta)$.

The XRD of pure $\mathrm{TiO}_{2}$ and $0.3 \% \mathrm{TiO}_{2}-\mathrm{Ag}$ related to the standard rutile (PDF\#73-1765) the characteristic peaks and the matching rate of the reciprocal of rutile were 0.7 and 3.7. This indicated that the two kinds of photocatalyst were the two structures coexist of anatase and rutile. The two phase formula (RIR) used to calculate the relative content of rutile phase (WA) and anatase phase 
(WB) for the two kinds of photocatalyst. This calculating result showed that the WA and WB were respectively $3.26 \%$ and $96.74 \%$ for $0.3 \% \mathrm{TiO}_{2}-\mathrm{Ag}$, but they were respectively $71.25 \%$ and $28.75 \%$. These results indicated that the anatase was the main phase when the $\mathrm{TiO}_{2}-\mathrm{Ag}$ prepared by the microwave hydrothermal method, while the pure $\mathrm{TiO}_{2}$ mainly containing rutile phase. It is thus clear that the $\mathrm{Ag}$ doped in $\mathrm{TiO}_{2}$ had great influence on crystal type which greatly inhibiting the $\mathrm{TiO}_{2}$ phase transformation from anatase to rutile, and anatase phase to rutile phase temperature was also improved. When the doping amount changed from $0.1 \%$ adding to $0.3 \%$, the crystal development of $\mathrm{TiO}_{2}-\mathrm{Ag}$ was complete, the crystallinity was increased, the grain size becoming larger. By combining with the degradation rate the best doping amount was gained which was $n\left(\mathrm{Ag}^{+}\right): \mathrm{n}\left(\mathrm{Ti}^{4+}\right)=0.002$ when the $\mathrm{TiO}_{2}$-Ag prepared by the microwave hydrothermal method.



Figure 3. XRD spectra of different doping amount of $\mathrm{TiO} 2-\mathrm{Ag}$ catalyst

SEM and EDS Analysis. The result from the morphology of $\mathrm{TiO}_{2}-\mathrm{Ag}$ catalyst as shown in Fig. 4 showed that the $\mathrm{TiO}_{2}-\mathrm{Ag}$ was tiny particles of nano sphere with uniform size and surface long pile and had the larger surface area at low magnification (Figure 4A) and high magnification (Figure 4B) which was conducive to the photocatalytic degradation of organic pollutants. Some of the crystals overlap, but the degree of aggregation was small. Good crystallinity and complete development improved catalyst activity.

Table 1 was the result of elemental analysis of $\mathrm{TiO}_{2}-\mathrm{Ag}$ catalyst in the specific micro region. The characteristic peaks of $\mathrm{Ti}, \mathrm{O}$ and $\mathrm{Ag}$ in the samples showed that it was feasible to synthesize $\mathrm{TiO}_{2-}$ $\mathrm{Ag}$ by microwave hydrothermal method. The total $\mathrm{Wt} \%$ and $\mathrm{At} \%$ of $\mathrm{Ti}$ and $\mathrm{O}$ in the samples of $\mathrm{TiO}_{2}-\mathrm{Ag}$ catalyst were close to $100 \%$. And more litter amount of $\mathrm{Ag}$ was doped in $\mathrm{TiO}_{2}-\mathrm{Ag}$ catalyst which was conformed with the reality.
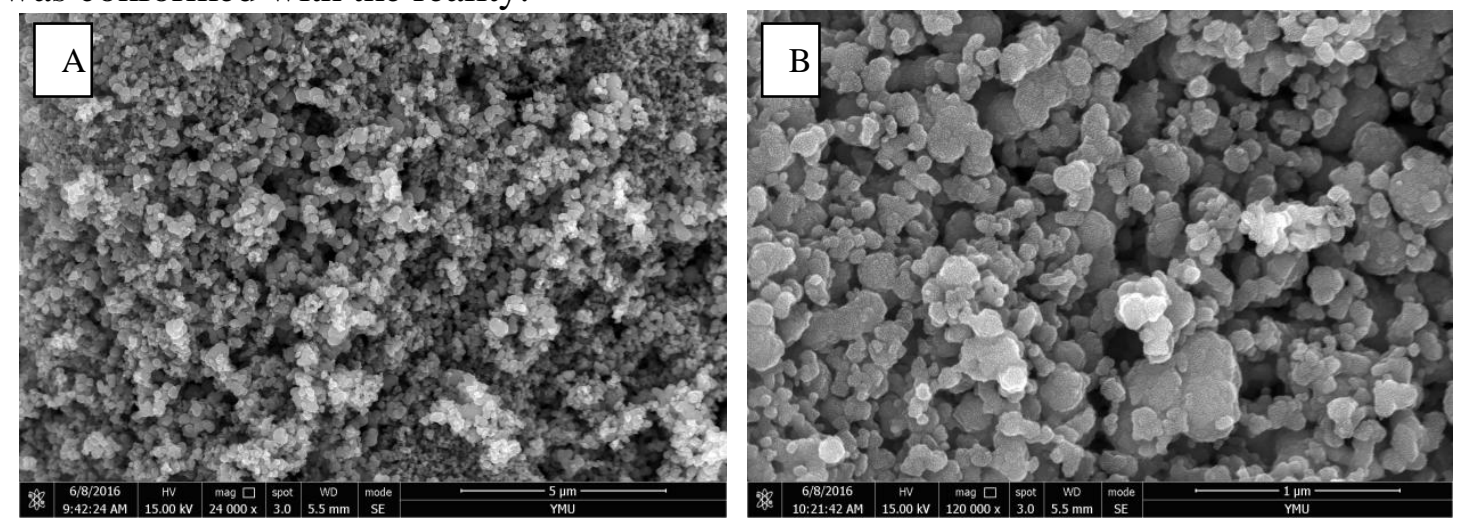

Figure 4. SEM diagram of $\mathrm{TiO} 2-\mathrm{Ag}$ under different magnification
(A.24000;
B. 120000) 
Table 1 TiO2-Ag measurement results of EDS

\begin{tabular}{lll}
\hline element & $\mathrm{Wt}[\%]$ & $\mathrm{At}[\%]$ \\
\hline OK & 43.12 & 69.47 \\
TiK & 56.64 & 30.48 \\
AgL & 0.23 & 0.06 \\
\hline
\end{tabular}

TG-DSC-DTG Analysis. The TG-DSC-DTG curves of doped $\mathrm{TiO}_{2}-\mathrm{Ag}$ and pure $\mathrm{TiO}_{2}$ catalysts was respectively shown in Fig. 5 and Fig. 6 (nitrogen as the purified gas and the heating rate 10 $\mathrm{K} / \mathrm{min}$ ).

The result from Fig. 5 showed that the curve could be divided into 3 stages. The first stage, the TG curve of $0 \sim 100^{\circ} \mathrm{C}$ range of weight loss was most serious, DSC curve had a peak temperature of $60^{\circ} \mathrm{C}$ strong exothermic peak which was of low boiling point organic matter decomposition and ethanol and water molecules caused by evaporation. Second order section, $100^{\circ} \mathrm{C} \sim 350^{\circ} \mathrm{C}$ range of weight loss had less, DSC curve had a peak temperature of $240^{\circ} \mathrm{C}$ strong endothermic peak which was the precursor of organic matter decomposition caused by combustion or tetrabutyl titanate. Third stages, weight loss was not obvious after $350{ }^{\circ} \mathrm{C}$, the DSC curve was exothermic phenomenon, turning at a temperature of $390^{\circ} \mathrm{C}, 721^{\circ} \mathrm{C}$ and $850^{\circ} \mathrm{C}$ respectively, of which $390^{\circ} \mathrm{C} \sim 721^{\circ} \mathrm{C}$ was $\mathrm{TiO} 2$ from amorphous anatase transition anatase temperature, $721^{\circ} \mathrm{C} \sim 850^{\circ} \mathrm{C}$ for grain size and crystal growth of anatase phase into rutile the temperature, and $850^{\circ} \mathrm{C} \sim 1000^{\circ} \mathrm{C}$ was due to a large number of anatase growth for rutile and rutile grain size.

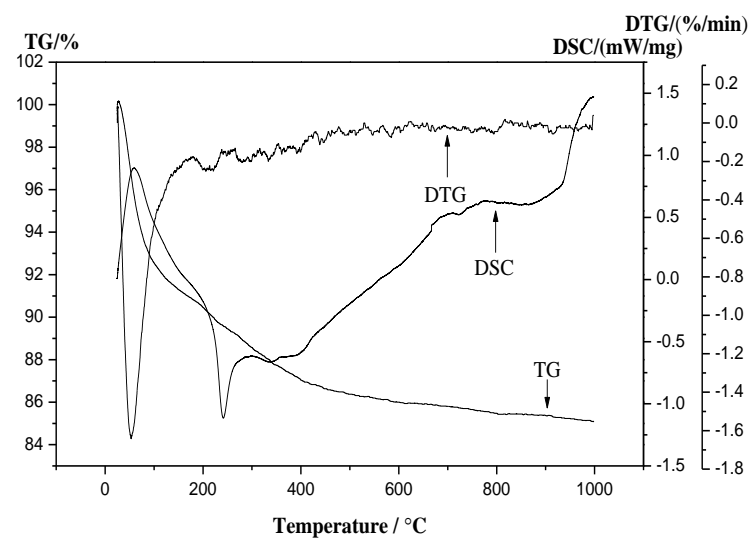

Figure 5. TG-DSC-DTG curve of $\mathrm{TiO}_{2}-\mathrm{Ag}$

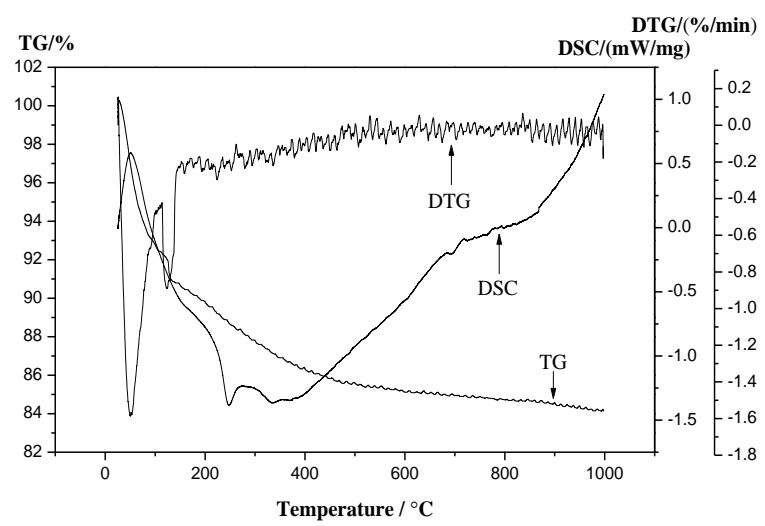

Figure 6. TG-DSC-DTG curve of $\mathrm{TiO}_{2}$

Fig. 5 and Fig. 6 for the peak reason was similar, but $\mathrm{TiO}_{2}-\mathrm{Ag}$ catalyst $\left(390^{\circ} \mathrm{C} \sim 721^{\circ} \mathrm{C}\right)$ from amorphous to anatase significantly was wider than $\mathrm{TiO}_{2}\left(335^{\circ} \mathrm{C} \sim 540^{\circ} \mathrm{C}\right)$ the temperature range which 
was conducive to the increase of anatase crystal particles, refinement of grain size and larger specific surface area. The results showed that the Ag doped influenced the composition of $\mathrm{TiO}_{2}$ catalyst and then did also the activity of the catalyst.

$\mathbf{N}_{2}$ Adsorption Desorption Analysis. The result of $\mathrm{TiO}_{2}-\mathrm{Ag}$ catalyst was investigated by $\mathrm{N}_{2}$ adsorption desorption analysis as shown in Fig. 7. According to the IUPAC classification ${ }^{[13]}$, the adsorption desorption curve of $\mathrm{TiO}_{2}-\mathrm{Ag}$ belonged to the IV isothermal adsorption curve, so the catalyst had the mesopore or macropore. In the relative pressure $\left(\mathrm{P} / \mathrm{P}_{0}\right)$ under the condition of 0.7 1.0 had obviously $\mathrm{H} 1$ type hysteresis loop, and illustration showed that mesoporous pore size distribution was relatively narrow and mesoporous material with uniform spherical size which was conducive to the photocatalytic degradation of organic pollutants.

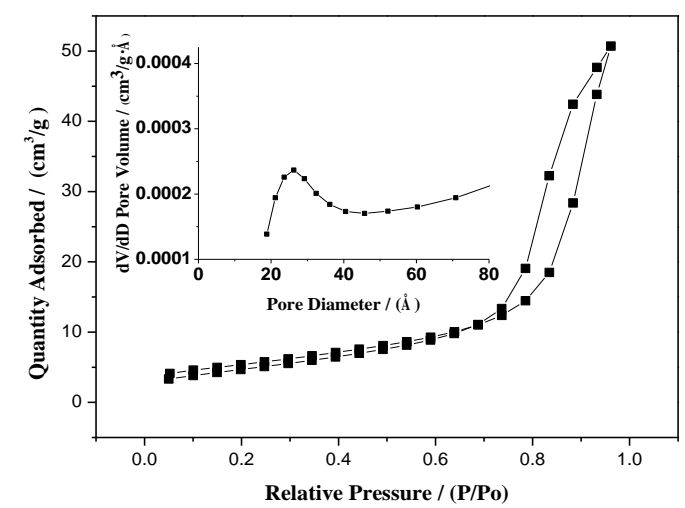

Figure 7. $\mathrm{N}_{2}$ adsorption-desorption isotherms and pore size distribution of $\mathrm{TiO}_{2}-\mathrm{Ag}$

ICP-AES Analysis. Table 2 was the result of ICP-AES of $\mathrm{TiO}_{2}-\mathrm{Ag}$ catalyst. The difference between the theoretical doping amount and the actual doping amount of the doped elements of the catalyst prepared by microwave hydrothermal method was small which indicated that the preparation of doped $\mathrm{TiO}_{2}-\mathrm{Ag}$ catalyst by microwave hydrothermal method had a high utilization rate of the drug.

Table 2 ICP-AES characterization result of TiO2-Ag

\begin{tabular}{l|l|l}
\hline element & Actual doping[\%] & Theoretical doping[\%] \\
\hline $\mathrm{Ag}$ & 0.16 & 0.20 \\
\hline
\end{tabular}

\section{Conclusion}

(1) The optimum conditions of $\mathrm{TiO}_{2}-\mathrm{Ag}$ photocatalyst prepared by microwave hydrothermal method were as follows: $\mathrm{n}\left(\mathrm{Ag}^{+}\right) / \mathrm{n}\left(\mathrm{Ti}^{4+}\right)=0.003$, microwave reaction power $600 \mathrm{~W}$, reaction temperature $140{ }^{\circ} \mathrm{C}$, reaction time $3 \mathrm{~h}$, calcination temperature $550^{\circ} \mathrm{C}$ and calcination time $3 \mathrm{~h}$.

(2) The degradation rate was $9.75 \%, 90.76 \%, 95.05 \%$ and close to $100 \%$ respectively by MW, UV, UV-MW and UV-MW-UT for 35 min degradation. The microwave irradiation and ultrasonic vibration could enhance the effect of $\mathrm{TiO}_{2}-\mathrm{Ag}$ on photocatalytic degradation of organic pollutants.

(3) The results from $\mathrm{TiO}_{2}-\mathrm{Ag}$ catalyst characterization showed that $\mathrm{Ag}$ doped had great influence on the crystal formation which inhibited the $\mathrm{TiO}_{2}$ phase transformation from anatase to rutile and improved from anatase phase to rutile phase temperature. The microwave hydrothermal method was feasible and had a high utilization rate of the catalyst. 


\section{References}

[1] Cui Yumin. Factors Influencing Photocatalytic Activity of Nano-TiO2. J. Chinese Jouranal of Rare Metals, 2006, 30(1):107-111.

[2] Cui Yumin, Fan Shaohua, Su Linghao. Photocatalytic degradation of acid black dyes by the functional material of titanium oxide. J. Journal of University of Science and Technology Beijing, 2006, 28(7):625-629.

[3] Sun Jing, Jiang Wenjian, Zhang Guiqin and etal. Preparation of Zn and N Co-doped TiO2 photocatalyst with microwave irradiation in ionic liquid and microwave strengthen photo-catalytic activity. J. Journal of Molecular Catalysis(China), 2013, 27(6):566-574.

[4] Wang Leiqing, Shi Zhongfen, Bi Xianjun. Preparation of copper doped TiO2 photo-catalysts with microwave irradiation in ionic liquid and microwave enhanced photo-catalytic activity. J. Applied Chemical Industry, 2014, 43(2):215-221.

[5] Zhang Mei, XuYaling, Bi Xianjun. Study on microwave-hydrothermal and sol-gel method synthesis of Er-doped $\mathrm{TiO} 2$ photocatalyst and its photo-chemistry performance. C. Advances in Computer Science Research-Management, Computer and Education Informatization, Paris: Atlantis Press, 2016:1204-1207.

[6] Zielinska A, Kowalska E, Sobczak JW and etal. Silver-doped TiO2 prepared by microemulsion method: Surface properties, bio- and photoactivity. J. Separation \& Purification Technology, 2010, 72(3):309-318.

[7] Alfaro S O, Rodríguez-González V, Zaldivar-Cadena A A and etal. Sonochemical deposition of silver-TiO2 nanocomposites onto foamed waste-glass: Evaluation of Eosin Y decomposition under sunlight irradiation. J. Catalysis Today, 2011, 166(1):166-171.

[8] Li Manwan, Zhang Mei, Bi Xianjun. Preparation of Y-doped TiO2 photo-catalysts with microwave irradiation in ionic liquid and microwave enhanced photo-catalytic activity. J. Chemical Research, 2016, 27(2):234-240.

[9] Li Manwan, Zhang Mei, Bi Xianjun. Preparation of Y-Ce doped with TiO2 photocatalyst in microwave ionic liquids and microwave enhanced photocatalytic activity. C. Advances in Computer Science Research-Management, Computer and Education Informatization, Paris: Atlantis Press, 2015:532-535.

[10]Zhang Mei, Lu Yuejie, Bi Xianjun. Preparation of Yb-Er doped with TiO2 photocatalyst in microwave ionic liquids and microwave enhanced photocatalytic activity. C. dvances in Computer Science Research-Management, Computer and Education Informatization, Paris: Atlantis Press, 2016:1362-1365.

[11]Zhai Chunyang, Zhou Weiqiang, Xu Jingku and etal. Preparation and properties of magnetic photocatalyst: TiO2-Fe3O4 loaded on active carbon. J. Chemical Research, 2009, 20(02):83-86.

[12] Li Yu, Han Zhaorang, Zhai Yongai and etal. Preparation and characterization of TiO2/SiO2 Composite Materials. J. Chemical Research, 2007, 18(01): 19-22.

[13] Hidaka H, AjisakaK, Horikosi S. Comparative assessment of the efficiency of TiO2/OTE thin film electrodes fabricated by three deposition methods: Photoelectrochemical degradation of the DBS anionic surfactant. J. Journal of Photochemistry and Photobiology A: Chemistry, 2001, 138(2):185-192. 